\title{
Temperature Integration at the AC Thermosensory Neurons in Drosophila
}

\author{
Xin Tang, ${ }^{1}$ Michael D. Platt, ${ }^{1}$ Christopher M. Lagnese, ${ }^{1}$ Jennifer R. Leslie, ${ }^{1}$ and Fumika N. Hamada ${ }^{1,2}$ \\ ${ }^{1}$ The Visual Systems Group, Division of Pediatric Ophthalmology, Cincinnati Children's Hospital Medical Center, Cincinnati, Ohio 45229, and ${ }^{2}$ Japan \\ Science and Technology Agency, Precursory Research for Embryonic Science and Technology, Saitama 332-0012, Japan
}

Temperature sensation has a strong impact on animal behavior and is necessary for animals to avoid exposure to harmful temperatures. It is now well known that thermoTRP (transient receptor potential) channels in thermosensory neurons detect a variable range of temperature stimuli. However, little is known about how a range of temperature information is relayed and integrated in the neural circuits. Here, we show novel temperature integration between two warm inputs via Drosophila TRPA channels, TRPA1 and Pyrexia (Pyx). The internal AC (anterior cell) thermosensory neurons, which express TRPA1, detect warm temperatures and mediate temperature preference behavior. We found that the AC neurons were activated twice when subjected to increasing temperatures. The first response was at $\sim 25^{\circ} \mathrm{C}$ via TRPA1 channel, which is expressed in the $\mathrm{AC}$ neurons. The second response was at $\sim 27^{\circ} \mathrm{C}$ via the second antennal segments, indicating that the second antennal segments are involved in the detection of warm temperatures. Further analysis reveals that $p y x$-Gal4-expressing neurons have synapses on the AC neurons and that mutation of $p y x$ eliminates the second response of the AC neurons. These data suggest that AC neurons integrate both their own TRPA1-dependent temperature responses and a Pyxdependent temperature response from the second antennal segments. Our data reveal the first identification of temperature integration, which combines warm temperature information from peripheral to central neurons and provides the possibility that temperature integration is involved in the plasticity of behavioral outputs.

\section{Introduction}

Temperature affects our lifestyle, as it conveys information about the environment and influences our comfort level. Animals need to process a variety of temperature stimuli appropriately to exhibit a proper behavioral response. ThermoTRP (transient receptor potential) channels, which are evolutionally conserved temperature sensors (Patapoutian et al., 2003; Dhaka et al., 2006; Venkatachalam and Montell, 2007), detect a wide range of temperatures and contribute to behaviors in many animals, including Drosophila (Tracey et al., 2003; Lee et al., 2005; Rosenzweig et al., 2005, 2008; Hamada et al., 2008; Kwon et al., 2008; Garrity et al., 2010; Gallio et al., 2011; Neely et al., 2011). ThermoTRP channels are expressed in distinct subsets of thermosensory neurons. However, it is unclear how a range of temperature information is processed and integrated into neural circuits. Drosophila exhibit a robust thermosensory response (Sayeed and Benzer, 1996; Hong et al., 2008; Dillon et al., 2009; Luo et al., 2010; Shen

Received April 18, 2012; revised Nov. 6, 2012; accepted Nov. 9, 2012.

Author contributions: X.T. and F.N.H. designed research; X.T., M.D.P., F.N.H., C.M.L., and J.R.L. performed research; X.T., M.D.P., and F.N.H. analyzed data; X.T. and F.N.H. wrote the paper.

This research was supported by a Trustee Grant from Cincinnati Children's Hospital, Japanese Science and Technology Agency/Precursory Research for Embryonic Science and Technology and March of Dimes to F.N.H. We are grateful to Dr. L. Liu for the pyx-Gal4 flies, Dr. L. Looger for the UAS-G-CaMP3.0 flies, Dr. Ben-Shahar for the pyx ${ }^{3}$ backcrossed flies, Dr. Garrity for $p y x^{3}$ and pyx $x^{3} ;$ pyxGe flies, and Bloomington Drosophila Stock Center at Indiana University. We thank Drs. Haruna Kaneko, Tadahiro Goda, Satoshi Namekawa, and Lauren M. Head for comments and advice on this manuscript.

Correspondence should be addressed to Fumika N. Hamada, 3333 Burnet Avenue, Cincinnati, $0 \mathrm{H} 45229$. E-mail: fumika.hamada@cchmc.org.

DOI:10.1523/JNEUROSCI.1894-12.2013

Copyright $\odot 2013$ the authors $\quad 0270-6474 / 13 / 330894-08 \$ 15.00 / 0$ et al., 2011). We therefore used Drosophila to address this question because they offer a relatively simple biological system coupled with powerful genetic and physiological tools that can provide the groundwork for the subsequent analysis of more complex systems (Olsen and Wilson, 2008; Griffith, 2012).

The antenna, a peripheral organ, is recognized as a temperature-sensing organ in many insects, including flies, based on its anatomical features and on physiological evidence (Altner et al., 1981; Altner and Loftus, 1985; Shanbhag et al., 1995; Sayeed and Benzer, 1996; Zars, 2001). In flies, the TRPP protein Brivido, which mediates cold detection, is expressed in the third antennal segments (Gallio et al., 2011), and several thermoTRP channels are expressed in the second antennal segments (Sun et al., 2009). However, it is unknown whether the second antennal segments are involved in temperature sensing.

We previously described a set of thermosensory neurons, AC (anterior cell) neurons, that are located in the brain and are required for the ability to select a preferred temperature (Hamada et al., 2008). The Drosophila TRPA channel TRPA1 is expressed in the AC neurons and is activated by warm temperatures over $\sim 25^{\circ} \mathrm{C}$ (Viswanath et al., 2003; Hamada et al., 2008). The identification of internal thermosensors was unexpected and therefore raised the question of why AC neurons would be located internally. Interestingly, further anatomical studies revealed that the soma of the AC neurons are located near the brain surface where the antennal nerves enter the brain (see Fig. 4D,F). Based on this anatomy, we hypothesized that peripheral thermosensory neurons in the antenna may directly send temperature information to the AC neurons to integrate temperature information. 

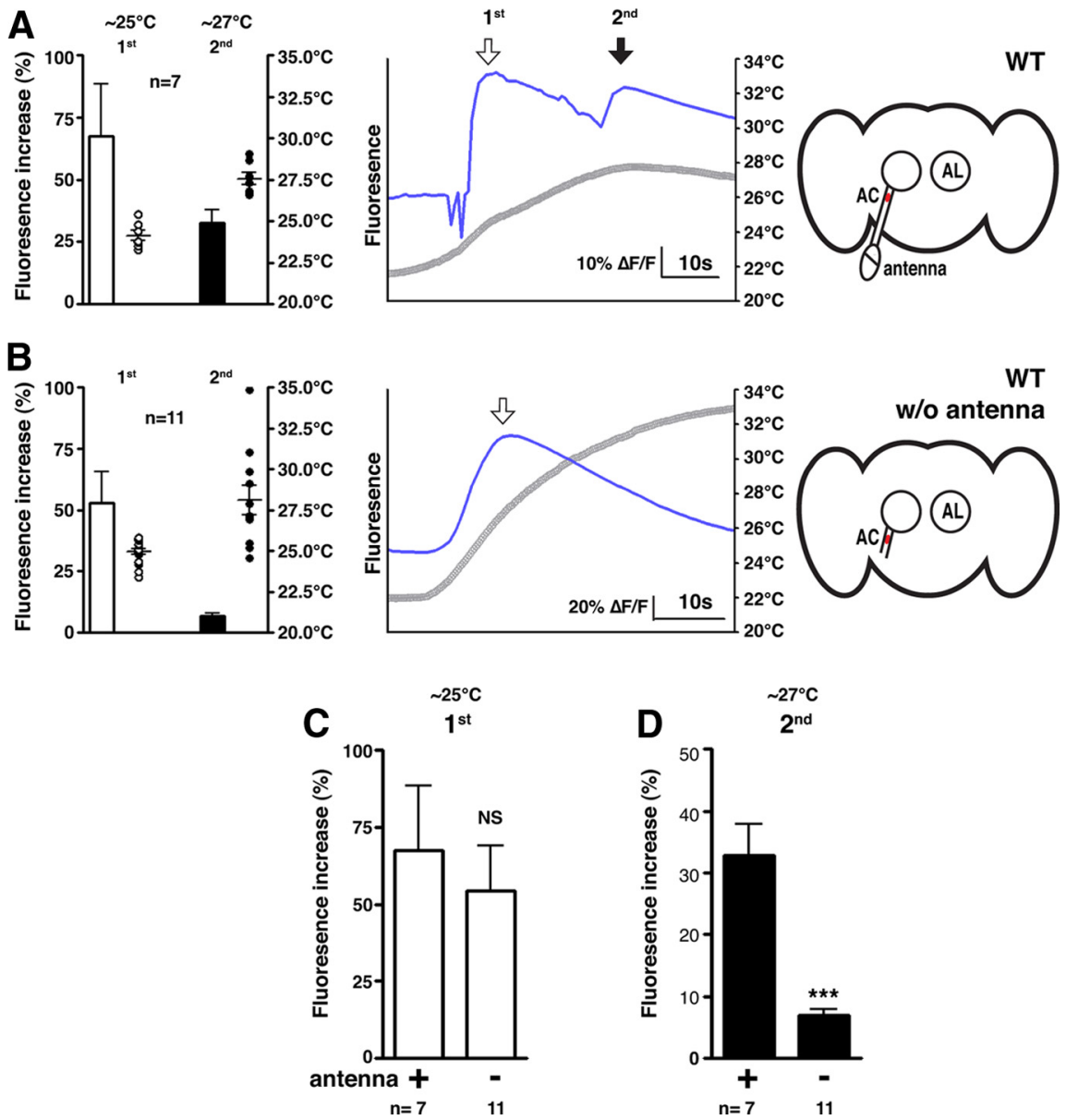

Figure 1. $A C$ neurons receive temperature inputs from the antennae. $A, B$, The warmth responses of $A C$ neurons were monitored with antenna ( $n=7$ neurons) $(\boldsymbol{A})$ and without antenna ( $n=11$ neurons) $(\boldsymbol{B})$ in $w^{1118}$ control flies. G-CaMP3.0 was expressed in the AC neurons using $\operatorname{TrpA}{ }^{\mathrm{SH}-\mathrm{Gal}}$. The $\mathrm{AC}$ neurons of the control flies were activated twice as the temperature increased $(A)$. The bar graph shows the mean percentage of fluorescence increase $(\Delta F / F)$ of the $A C$ neurons during the first response at $\sim 25^{\circ} \mathrm{C}$ (white bar) and during the second response at $\sim 27^{\circ} \mathrm{C}$ (black bar). The circles show the peak temperatures of the experiments in each category. The number of circles represents the number of assays. Error bars are the SEM. The line graph shows a representative experiment, comparing the fluorescence changes $(\Delta F / F)$ (blue line) and the temperature change (gray line). The background fluorescence was subtracted from the mean fluorescent intensity of the $A C$ neurons. The diagrams represent the fly brains. AL, Antennal lobe. $\boldsymbol{C}, \boldsymbol{D}$, The comparison between the first $(\boldsymbol{C})$ and second $(\boldsymbol{D})$ responses of the $A C$ neurons in the wild-type with ( $n=7$ neurons) and without antenna ( $n=11$ neurons). The same bar graph data from $\boldsymbol{A}$ and $\boldsymbol{B}$ were used in $\boldsymbol{C}$ and $D$. The bar graph shows the mean percentage of fluorescence increase $(\Delta F / F)$ of the $A C$ neurons during the first response at $\sim 25^{\circ} \mathrm{C}$ (white bar, $\boldsymbol{C}$ ) and during the second response at $\sim 27^{\circ} \mathrm{C}$ (black bar, $\boldsymbol{D}$ ). Significance was determined using unpaired $t$ test compared with and without antenna; ${ }^{* * *} p<0.001$. Error bars are the SEM.

Here, we propose that novel warm temperature integration occurs in the AC neurons. This initial identification of temperature integration may facilitate an understanding of the mechanisms of not only temperature detection in the fly but also other sensory integration. Because of the importance of TRP channels for pain, touch, smell, taste, hearing, and vision (Damann et al., 2008), our study of temperature integration may contribute to a greater understanding of other sensory systems.

\section{Materials and Methods}

Fly strains. Unless specifically addressed, the fly strains used in this study were received from Bloomington Drosophila Stock Center at Indiana University. The following fly lines were used: $\operatorname{Trp} A 1^{S H}-$ Gal4 and $\operatorname{Trp} A 1^{\text {ins }}$ (Hamada et al., 2008); pyx-Gal4 (Sun et al., 2009); UAS-G-CaMP3.0 (Tian et al., 2009); $p a i n^{1}$ (Tracey et al., 2003); $p y x^{3}$ and $p y x^{3} ; p y x G e$ (Lee et al., 2005), which were used for the calcium imaging; and $p y x^{3}$ (backcrossed to Canton-S) (Sun et al., 2009), which were used for the behavioral experiments. Instruments).
Immunohistochemistry. Immunostaining was performed as described previously (Hamada et al., 2008). Antibodies were used at the following dilutions: rat anti-TRPA1 (1:1000), mouse anti-GFP (1:200; Millipore Bioscience Research Reagents), rabbit anti-RFP (1:200; Millipore Bioscience Research Reagents), goat anti-rat Cy3 (1:4000; Jackson ImmunoResearch), goat anti-rat Cy5 (1:200; Jackson ImmunoResearch), goat anti-rabbit Cy3 (1:200; Jackson ImmunoResearch), and goat antimouse Cy5 (1:200, Jackson ImmunoResearch).

G-CaMP imaging. Brain preparation was modified based on the previously described protocol (Hamada et al., 2008). Calcium imaging was obtained from $\operatorname{TrpA1}^{\mathrm{SH}}{ }_{-}$Gal4; UAS-GCaMP3.0 flies of either sex using wild-type (WT; $w^{1118}$ ), pain ${ }^{1}, p y x^{3}, p y x^{3} ; p y x G e$ ( pyx minigene with $\left.p y x^{3}\right)$, and $\operatorname{Tr} p A 1^{\text {ins }}$. Fly brains were dissected in modified standard solution $\mathrm{F}$ (5 mм Na-HEPES, $115 \mathrm{~mm} \mathrm{NaCl}, 5 \mathrm{~mm} \mathrm{KCl}, 6$ $\mathrm{mm} \mathrm{CaCl}_{2}, 1 \mathrm{~mm} \mathrm{MgCl}_{2}, 4 \mathrm{~mm} \mathrm{NaHCO}, 5 \mathrm{~mm}$ trehalose, $10 \mathrm{~mm}$ glucose, $65 \mathrm{~mm}$ sucrose, $\mathrm{pH}$ 7.5) (Ng et al., 2002). The brain samples were isolated from the peripheral tissues, but the antennae remained connected to the brain to analyze the effect of the antennae on AC neurons. The eyes, proboscis, and cuticle of the head were removed using fine forceps to avoid damaging the antennae and antennal nerves; only the antennae and a small piece of the surrounding cuticle remained attached to the anterior side of the brain via the antenna nerve. The prepared brain samples were mounted on a laminar flow perfusion chamber beneath the $40 \times$ water-immersion objective of a fixedstage upright microscope (Axio Examiner.Z1; Zeiss). During the experiments, the preparations were continually perfused with modified standard solution F. The perfusion solution was quickly heated to $\sim 45^{\circ} \mathrm{C}$ using a CL-100 bipolar temperature controller equipped with an SC-20 dual in-line solution heater/cooler (Warner Instruments). The perfusion solution was added directly on one side of the brain sample to heat the preparation. The brain sample was placed directly below the objective. Because it was impossible to place the thermocouple very close to the brain during the experiments, it was placed in the bath on the opposite side from the entrance of the perfusion solution. Therefore, the bath temperature was used as an index for the calcium imaging experiments.

Optical images of the preparation were acquired during the temperature shift using a digital CCD camera (C10600-10B-H; Hamamatsu) at 4 frames per second with $512 \times 512$ pixel resolution. The data in each image were digitized and analyzed using AxonVision 4.8.1 (Zeiss). For analysis, the mean fluorescent intensity of the somas of the AC neurons was calculated for each frame. Concurrently, the background fluorescence (calculated from the average fluorescence of two randomly chosen non-G-CaMP-expressing areas) was subtracted from the mean fluorescent intensity of the regions of interest for each frame. Background-subtracted values were then expressed as percentage $\Delta F / F$, where $F$ is the mean fluorescence intensity before stimulation. The temperature of solution $F$ was simultaneously recorded and digitized using DI-158U and WinDAQ acquisition software (DataQ

Temperature preference assays. Temperature preference assays were performed as described previously (Hamada et al., 2008). Each behav- 
ioral assay was performed for $30 \mathrm{~min}$ in an environmental room maintained at $25^{\circ} \mathrm{C} / 65-70 \%$ relative humidity. The flies of either sex were raised under LD (light $12 \mathrm{~h} /$ dark $12 \mathrm{~h}$ ) conditions, and the behavioral experiments were performed at zeitgeber time 7-9. The preferred temperature was determined by examining the distribution of flies exhibiting temperature preference behavior.

\section{Results}

AC neurons receive temperature signals from the antennae To assess the functional interactions between the AC neurons and the antennae, we first determined whether the AC neurons receive temperature information from the antennae. We used a calcium indicator, G-CaMP3.0, to record the activity of the AC neurons as they were subjected to increasing temperatures (Tian et al., 2009). G-CaMP3.0 was expressed in the AC neurons via TrpA1-Gal4 (Hamada et al., 2008), and changes in the fluorescence of the AC neurons were measured. Brain samples were isolated from the peripheral tissues, but the antennae were left connected to the brain when the effects of the antennae on AC neurons were analyzed (Fig. 1).

When the brain samples included intact antennae, the G-CaMP3.0 fluorescence in the AC neurons peaked at both $25^{\circ} \mathrm{C}$ and $27^{\circ} \mathrm{C}$ as the temperature increased (Fig. $1 A$ ). This result indicates that $\mathrm{AC}$ neurons exhibit two warmth responses when the antennae are intact. For the rest of the study, we refer to the first peak in fluorescence at the lower temperature $\left(\sim 25^{\circ} \mathrm{C}\right)$ as the "first response" of the AC neurons and to the second peak at the higher temperature $\left(\sim 27^{\circ} \mathrm{C}\right)$ as the "second response." Interestingly, when the antennae were removed, the second response of the AC neurons was almost abolished (Fig. $1 B$ ), with the second response of the flies with antenna being significantly higher than the flies without antenna (Fig. $1 D ; t_{(16)}=6.263, p<10^{-4}$ ). In contrast, the first response of the AC neurons $\left(\sim 25^{\circ} \mathrm{C}\right)$ was not significantly different $\left(t_{(16)}=0.5155, p=0.6133\right)$ regardless of whether the antennae remained connected (Fig. 1C). The data suggest that the second response $\left(\sim 27^{\circ} \mathrm{C}\right)$ of the $\mathrm{AC}$ neurons is dependent on the antennae.

To further support the assertion that the second response is an antennal response to $\sim 27^{\circ} \mathrm{C}$ and not a delayed response of the AC neurons to antennal neurons activated by $\sim 25^{\circ} \mathrm{C}$, we analyzed the correlation between the time intervals between the first and second responses and the rate of temperature increase (data not shown). We found that the time interval between the first and second response changes with the rate of temperature increase; when the rise in temperature is faster, the interval between the first and second peaks shortens. This result suggests that $\mathrm{AC}$ neurons and antennae are indeed detecting distinct temperatures.

We previously showed that TRPA1 is responsible for detecting warm temperatures in the AC neurons (Hamada et al., 2008). However, because we used brain samples in which the antennae were removed, it remains unclear whether TRPA1 is required for the first or second response of the AC neurons. To settle this point, we used $\operatorname{Tr} p A 1^{\text {ins }}$ mutant brains with intact antennae (Fig. 2 ). We found that the first responses in the $\operatorname{Trp} A 1^{\text {ins }}$ mutants with antennae $(p=0.0137)$ and without antennae $(p=0.0014)$ were significantly smaller than that of WT (Fig. $2 A ; F_{(3,38)}=8.22, p=$ $0.0002)$. In the second responses, $\operatorname{Tr} p A 1^{\text {ins }}$ mutants with antennae were not significantly different from those of WT $(p=0.1569)$. When the antennae of the $\operatorname{Tr} p A 1^{i n s}$ mutants were removed, the second responses of the AC neurons were abolished $(p=0.0017)$, which was consistent with WT (Fig. $2 B ; F_{(3,38)}=15.41, p<10^{-4}$ ). Therefore, we conclude that the first response of the AC neu-
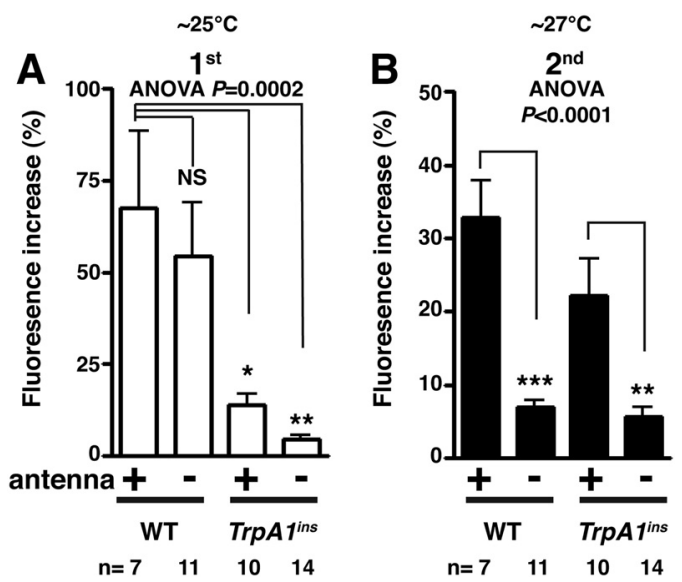

Figure 2. TRPA1 is necessary for the first response but not the second response of the $A C$ neurons. $\boldsymbol{A}, \boldsymbol{B}, \mathrm{G}$-CaMP3.0 was expressed in the AC neurons using $\operatorname{TrpA} 1^{\mathrm{SH}-} \mathrm{Gal} 4$ in the WT and $\operatorname{TrpA} 1^{\text {ins }}$ background. Warmth responses of $A C$ neurons were monitored with antenna in WT ( $n=7$ neurons), without antennae in WT ( $n=11$ neurons), with antenna in $\operatorname{TrpA}^{\text {ins }}$ ( $n=10$ neurons), and without antennae in $\operatorname{TrpA}^{\text {ins }}$ ( $n=14$ neurons). The same WT data from Figure 1 were used in Figure 2. The bar graph shows the mean percentage of fluorescence increase $(\triangle F / F)$ of the $A C$ neurons during the first response at $\sim 25^{\circ} \mathrm{C}$ (white bar, $\boldsymbol{A}$ ) and during the second response at $\sim 27^{\circ} \mathrm{C}$ (black bar, $\boldsymbol{B}$ ). One-way ANOVA with the Tukey's post hoc test was used to determine pairwise differences between groups; ${ }^{*} p<0.05,{ }^{* *} p<0.01$, and ${ }^{* * *} p<$ 0.001. Error bars are the SEM.

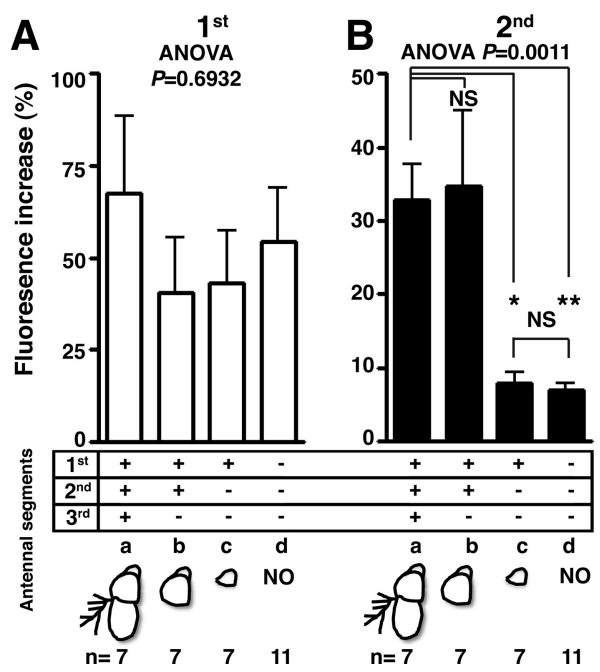

Figure 3. The second response of the $A C$ neurons arises from the second antennal segments $\boldsymbol{A}, \boldsymbol{B}, \mathrm{G}-\mathrm{CaMP} 3.0$ was expressed in the AC neurons using TrpA1 ${ }^{\mathrm{SH}-\mathrm{Gal} 4}$ in the WT background. The fly antenna is composed of three segments, as depicted in the diagrams ( $a$, intact antenna, $n=7$ neurons; $b$, third antenna removal, $n=7$ neurons; $c$, second and third antennae removal, $n=7$ neurons; $\mathrm{d}$, no antenna, $n=11$ neurons). The bar graph shows the mean percentage of fluorescence increase $(\Delta F / F)$ of the $A C$ neurons during the first response at $\sim 25^{\circ} \mathrm{C}$ (white bar, $\boldsymbol{A})$ and during the second response at $\sim 27^{\circ} \mathrm{C}$ (black bar, $\boldsymbol{B}$ ). Each response was compared with the other responses of flies with various antenna ablations. One-way ANOVA with the Tukey's post hoc test was used to determine pairwise differences between groups; ${ }^{*} p<0.05$ and ${ }^{* *} p<0.01$. Error bars are the SEM.

rons is TRPA1 dependent and that the second response is antenna dependent.

The second antennal segments are responsible for the second response of the AC neurons

In a Drosophila antenna, two structures in the third antennal segments, the arista and the sacculus, are responsible for detecting temperatures (Shanbhag et al., 1995; Gallio et al., 


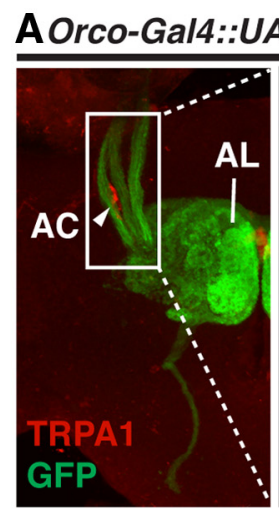

C
B

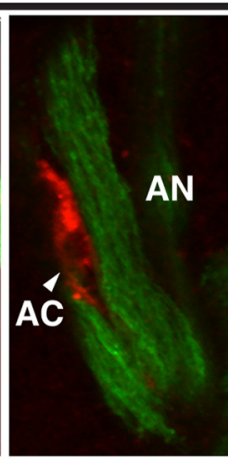

\section{F-Gal4::UAS-mCD:GFP}

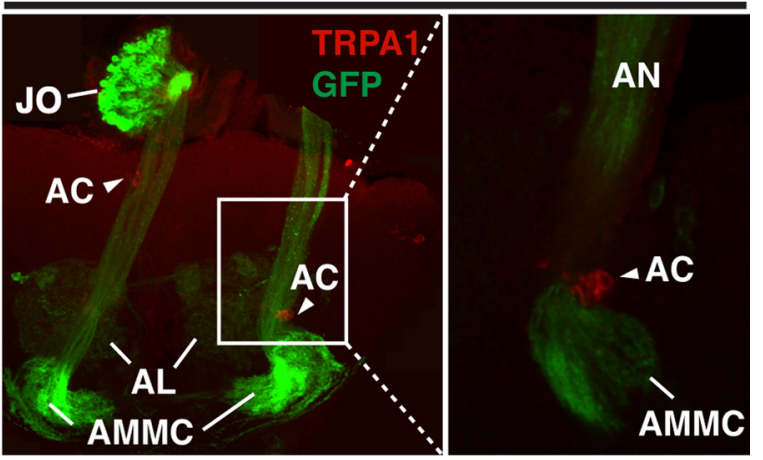

c155-Gal4::UAS-SyteGFP
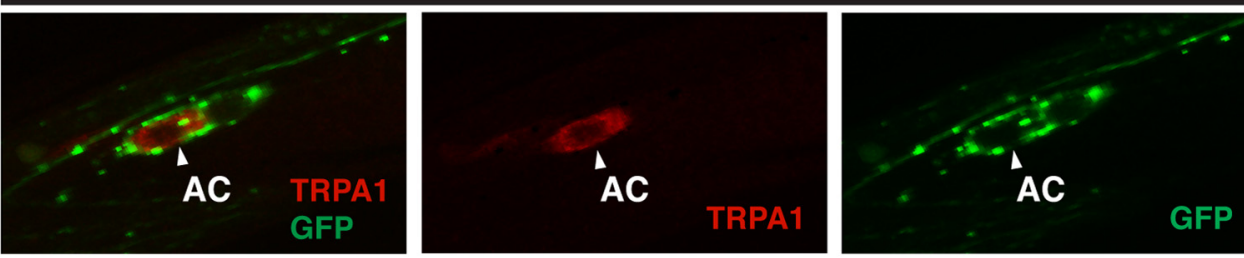

D1 pyx-Gal4::UAS-mCD:RFP

E pain-Gal4::UAS-mCD:GFP
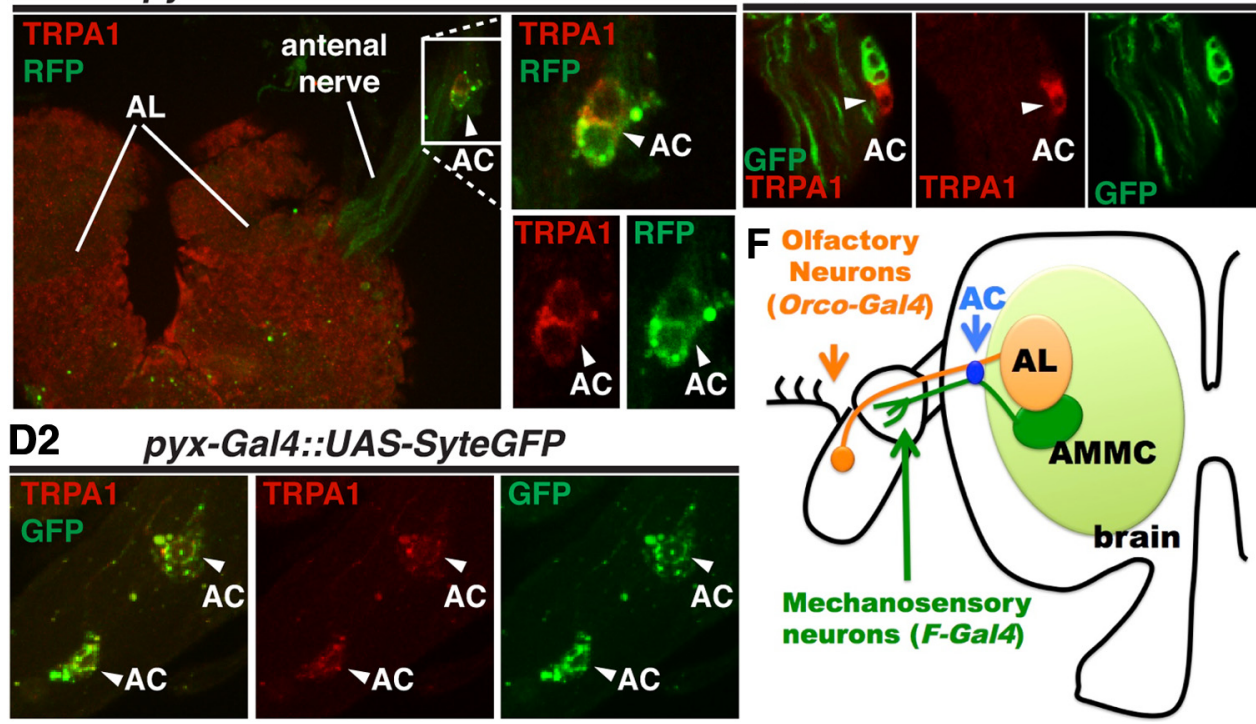

Figure 4. AC neurons receive projections from pyx-Gal4-expressing neurons. $A, B$, The flies were stained with anti-GFP (green) and anti-TRPA1 (red). AC neurons (arrowhead) were specifically labeled using anti-TRPA1 antisera. Orco-Gal4::UAS-mCD:GFP labels olfactory neurons $(\boldsymbol{A})$ and $F-G a l 4:: U A S-m C D$ :GFP labels mechanosensory neurons $(\boldsymbol{B})$, but neither of these overlapped with the somas of the AC neurons. C, D, The flies showed overlapping of membrane RFP (green) or synaptic GFP (green) with AC neurons (red). C, c155-Gal4::UAS-SyteGFP (synaptic GFP) with anti-GFP (green) and anti-TRPA1 (red) (D1) pyx-Gal4:: UAS-mCD:RFP with anti-RFP (green) and anti-TRPA1 (red), (D2) pyx-Gal4:: UAS-syteGFP with anti-GFP (green) and anti-TRPA1 (red). E, pain-Gal4:: UAS-mCD:GFP with anti-GFP (green) did not overlap with AC neurons (red), but overlapped with the cells right next to the AC neurons. $F$, A schematic of the fly brain and antennae. The AC neurons are shown in blue. The soma belongs to neither mechanosensory neurons (F-Gal4) nor olfactory neurons (Orco-Gal4). AL, Antennal lobe; AN, antennal nerve; J0, Johnston's organ; AMMC, antennal mechanosensory and motor center.

2011). The arista has both heat- and cold-responsive cells, whereas the sacculus senses cold temperatures via a TRPP protein, Brivido (Gallio et al., 2011). To determine whether these structures are responsible for the second response of the AC neurons, we surgically ablated the third antennal segments and measured the second response (Fig. 3). As a control experiment, the first response of the AC neurons was not significantly altered by any antennal ablation preparation, regardless of the antennae's existence (Fig. $3 A ; F_{(3,28)}=0.4883, p=0.6932$ ). Interestingly, removal of the third segment of the antenna did not reduce the amplitude of the second response (Fig. $3 B, \mathrm{~b} ; p=$ 0.9946), suggesting that the third antennal segments are not responsible for the second response of the AC neurons.
To identify which antennal segments are responsible for the second response, we further removed each segment of the antennae and tested the activity of the AC neurons. When we removed the second antennal segments, we found that the second response of the $\mathrm{AC}$ neurons decreased significantly (Fig. $3 B, c ; p=0.0148$ ), suggesting that the second antennal segments are necessary for the second response. When we removed all three segments of the antennae, the second response of the AC neurons decreased significantly (Fig. $3 B$, $\mathrm{d} ; p=0.0046)$. However, it did not cause a further decrease in the second response of the AC neurons compared with removing both the second and third segments $(p=0.9993)$. Therefore, we confirmed that the second antennal segments are responsible for the second response (Fig. $3 B ; F_{(3,28)}=8.931, p=0.0011$ ). 
pyx-Gal4 neurons synapse directly on the AC neurons

The second antennal segments are composed of the Johnston's organ, a chordotonal organ that functions in gravity sensing and hearing (Göpfert and Robert, 2002; Kim et al., 2003; Kamikouchi et al., 2009; Yorozu et al., 2009; Effertz et al., 2011). Five TRP channels are expressed in the second antennal segments, based on promoterGal4 expression (Sun et al., 2009). These TRP channels include the TRPA channels Pyrexia (Pyx) (Lee et al., 2005) and Painless (Pain) (Tracey et al., 2003), the TRPN channel NompC (Walker et al., 2000), and the TRPV channels Nanchung (Nan) (Kim et al., 2003) and Inactive (Iav) (Gong et al., 2004). Specifically, Pyx and Pain are temperaturesensing receptors that are directly activated by temperatures above $38^{\circ} \mathrm{C}$ and $42^{\circ} \mathrm{C}$, respectively (Lee et al., 2005; Sokabe et al., 2008). The pain gene is important for avoiding noxious heat, and $p y x$ is involved in thermotolerance in adult flies (Tracey et al., 2003; Lee et al., 2005). In addition, iav is necessary for larval thermostatic behavior (Kwon et al., 2010). However, it is unknown whether the second antennal segments are involved in temperature detection.

To determine which, if any, of these TRP channels is responsible for the second response of the AC neurons, we first tried to monitor the direct temperature responses in the second antennal segments using G-CaMP3.0. Unfortunately, the surfaces of the second antennal segments exhibit strong autofluorescence that disturbed the monitoring of the G-CaMP fluorescence change (data not shown). We therefore used anatomical approaches to determine whether TRP channel-expressing neurons project to AC neurons.

The antennal nerves are composed mainly of two different sensory bundles (Fig. $4 F$ ): one from the olfactory neurons in the third antennal segments and the other from Johnston's organ in the second antennal segments (Kamikouchi et al., 2006). These neurons were labeled with Orco-Gal4 (olfactory neurons) (Fig. $4 A$ ) and F-Gal4 (mechanosensory neurons), respectively (Fig. 4B). To determine whether these neural bundles overlap with the somas of the AC neurons, we used these Gal4s driving either membrane-targeted GFP (UAS- $m C D: G F P)$, membrane-targeted RFP (UAS- $m C D: R F P)$, or GFP-tagged synaptic marker (UAS-syteGFP) and performed immunostaining with anti-TRPA1 to label the AC neurons (Fig. 4A,B). However, neither Orco-Gal4 nor F-Gal4 neurons overlapped with the somas of the AC neurons (Fig. $4 F$ ), despite the fact that F-Gal4 labeled most of the neurons in Johnston's organ (Kamikouchi et al., 2006). Interestingly, we found that only c155-Gal4 (panneuronal Gal4) and pyx-Gal4 neurons overlapped with the somas of the AC neurons (Fig. 4C,D), but the other TRP channels Gal4s: painless-Gal4 (Fig. 4E), iav-Gal4, and nompC-Gal4 (data not shown) did not. This result suggests that pyx-Gal4-expressing neurons project to and synapse on the AC neurons.

\section{The second warmth response in AC neuron is Pyrexia dependent}

To determine whether Pyx contributes to the second response of the AC neurons, we analyzed the activity of the AC neurons in null mutants, $p y x^{3}$ (Lee et al., 2005) (Fig. 5A,C) and $p y x^{3} /$ $D f(3 L) E D 201$ flies (Fig. $5 C$ ). In these mutant flies, the AC neurons exhibited only the first responses (Fig. $5 C ; F_{(4,35)}=0.4669$, $p=0.7595)$, whereas the second responses of AC neurons in $p y x^{3}$ $\left(p<10^{-4}\right)$ and $p y x^{3} / D f(3 L) E D 201\left(p<10^{-4}\right)$ flies were significantly smaller than those of WT (Fig. $5 D ; F_{(4,35)}=11.13, p<$ $\left.10^{-4}\right)$, suggesting that Pyx is important for the second response. To determine whether Pyx expression is sufficient to rescue the $p y x^{3}$ phenotype, we used genomic $p y x$ rescue fly lines ( $p y x^{3}$; py $x \mathrm{Ge}$ ) to test the second response of the AC neurons (Fig. $5 D$ ). These flies exhibited the significant fluorescence increase of the second response of the AC neurons $(\sim 20 \%)$ comparing $p y x^{3}$ $(p=0.0120)$ and $p y x^{3} / D f(3 L) E D 201(p=0.0393)$. Therefore, 

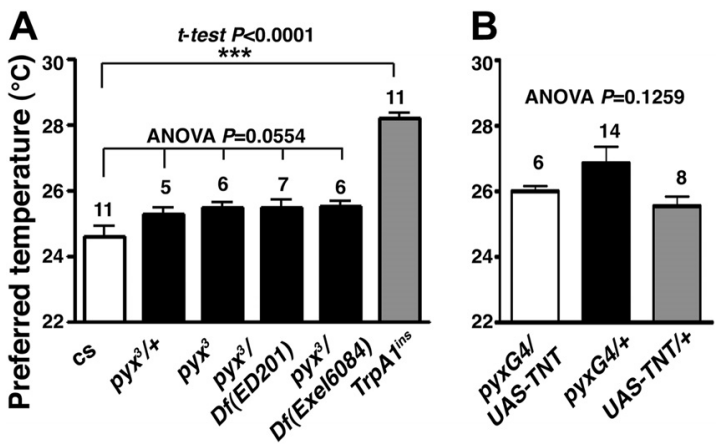

Figure 6. Disruption of pyrexia did not change temperature preference behavior. $A$, Mean preferred temperatures of wild-type (cs) ( $n=11$ independent assays), $p y x^{3} /+(n=5$ independent assays), $p y x^{3}$ ( $n=6$ independent assays), $p y x^{3} / D f(3 L) E D 201$ ( $n=7$ independent assays), pyx $x^{3} / D f(3 L)$ Exel6084 ( $n=6$ independent assays), and $\operatorname{TrpA}{ }^{\text {ins }}$ mutant flies ( $n=11$ independent assays). pyx ${ }^{3}$ flies were backcrossed to Canton-S (cs). TrpA $7^{\text {ins }}$ mutant flies preferred a significantly higher temperature compared with wild type. Significance was determined using unpaired $t$ test compared WT and $\operatorname{TrpA} 7^{\text {ins }}$ mutants, ${ }^{* * *} p<0.001$. Error bars are the SEM. The mean preferred temperatures of $p y x^{3}$ mutant flies and two $p y x^{3} / D f$ flies were not significantly different compared with wild-type and $p y x^{3} /+$ flies. One-way ANOVA with the Tukey's post hoc test was used to determine pairwise differences between groups. $\boldsymbol{B}$, TNT expression driven by pyx-Gal4 ( $n=6$ independent assays) did not cause a significant change of the preferred temperature compared with two control flies pyx-Gal4/ $+(n=14$ independent assays) and UAS-TNT/+ ( $n=8$ independent assays). One-way ANOVA was used, $p=0.1259$.

Pyx expression is sufficient for the second response of the AC neurons.

Furthermore, because Pain is activated by warm temperatures (Sokabe et al., 2008), we tested the first and second responses of the AC neurons using pain ${ }^{1}$ mutants as a control (Fig. 5B) (Tracey et al., 2003). We found that the fluorescent increase of the second responses in pain ${ }^{l}$ mutants was not significantly different from that of the responses observed either in WT $(p=0.0648)$ or in $p y x^{3} ; p y x G e(p=0.9967)$ flies (Fig. $\left.5 D\right)$. Therefore, we concluded that Pain does not affect the second response. Together, our data show that the second warmth response in AC neurons is Pyx dependent.

\section{pyrexia is not responsible for temperature preference behavior}

We previously showed that the AC neurons are responsible for temperature preference behavior (Hamada et al., 2008). We therefore tested whether $p y x$ might play a role in temperature preference behavior (Fig. 6A). Although we used the $p y x^{3}$ flies that backcrossed to Canton-S (cs), we failed to see a significant difference in the temperature preference behavior between $c s$, $p y x^{3} /+, p y x^{3}, p y x^{3} / D f(3 L) E D 201$, and $p y x^{3} / D f(3 L)$ Exel 6084 flies $\left(F_{(4,30)}=2.608, p=0.0554\right)$. The preferred temperature of $\operatorname{Trp} A 1^{\text {ins }}$ mutant flies, however, was significantly higher than that of WT $\left(t_{(20)}=10.36, p<10^{-4}\right)$ as previously reported (Hamada et al., 2008). Notably, $p y x^{3}$ mutants have been reported to experience a more rapid paralysis over $40^{\circ} \mathrm{C}$ (Lee et al., 2005), but they do not exhibit a significantly different temperature preference. We further used flies that expressed TNT, a tetanus toxin, which inhibits synaptic transmission in pyx-expressing neurons and tested temperature preference behavior. However, pyx-Gal4/ $U A S-T N T$ flies did not prefer a significantly different temperature compared with the control pyx-Gal4/+ and UAS-TNT/+. (Fig. $6 B ; F_{(2,25)}=2.254, p=0.1259$ ). These data suggest that $p y x$ is not responsible for temperature preference behavior.

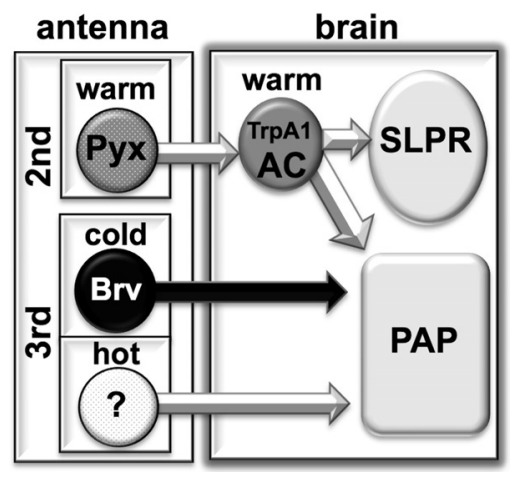

Figure 7. Temperature neural circuits from antennae to brain. Schematic of the temperature neural circuits based on this manuscript and on other studies (Hamada et al., 2008; Sun et al. 2009; Gallio et al., 2011). Based on the Gal4 expression data, Pyx is expressed in the second antennal segments, and Brv is expressed in the third antennal segments.

\section{Discussion}

Understanding mechanisms of sensory integration is an important concept in neuroscience because animals need to change their behavioral response depending on environmental stimuli (Ramot et al., 2008; Luo et al., 2010; Neely et al., 2010; Beverly et al., 2011; Lahiri et al., 2011; Shen et al., 2011; Sugi et al., 2011). It is well known that thermoTRP channels in thermosensory neurons detect temperature stimuli (Patapoutian et al., 2003; Caterina, 2007). However, little is known about the mechanisms that control how a range of temperature information is relayed by the neural circuitry. We now show that internal AC thermosensory neurons integrate two different warm temperature inputs: their own TRPA1 temperature response (Hamada et al., 2008) and one from the second antennal segments (Figs. 1-3). The temperature inputs from the second antennal segments may modulate the activity of AC neurons, which affect the overall temperature neural circuits (Bargmann, 2012). Given the prevailing view that sensory neurons do not normally receive inputs from other neurons, we have identified a unique feature of AC thermosensory neurons.

We and others previously described the temperature neural circuit from the antennae to the brain (Hamada et al., 2008; Gallio et al., 2011). Both hot and cold sensory neurons from the third antennal segments project to the PAP (proximal-antennalprotocerebrum), whereas the AC neurons project to both the PAP and the SLPR (superior lateral protocerebrum) (Fig. 7). We demonstrated that the AC neurons receive Pyx-dependent temperature inputs (Fig. 5) from the second antennal segments (Fig. 3 ) and that pyx-Gal4-expressing neurons synapse on the AC neurons (Fig. 4D). Therefore, our data suggest the possibility that Pyx-expressing neurons in the second antennal segments detect warm temperatures and directly convey warmth information to the AC neurons. However, because endogenous Pyx expression has not been clearly identified, it is important to observe whether endogenous Pyx-expressing neurons in the second antennal segment directly respond to warm temperatures. Additionally, we do not exclude the possibility that the Pyx neurons synapses on the AC neurons may come from the second and third antennal segments because pyx-Gal4 appears not only in $\sim 50$ cells of the Johnston's organ in the second antennal segments but also in some cells of the third antennal segments (Sun et al., 2009). Nonetheless, our data clearly indicate that the second antennal segments and Pyx are responsible for warm temperature detection and that this information is transmitted to the AC neurons. Therefore, we suggest a foundation of the temperature neural 
circuits through the addition of a Pyx-dependent warmth sensing circuit from the second antennal segments (Fig. 7).

Although Pyx channels are activated at more than $\sim 38^{\circ} \mathrm{C}$ (Lee et al., 2005), our data indicate that the Pyx-dependent temperature response is observed at more than $\sim 27^{\circ} \mathrm{C}$, when we used the bath temperature as an index for the calcium imaging (Fig. 5) (see the Materials and Methods). To determine the difference in temperatures between the actual brain and the bath, a thermometer was placed directly below the objective where the brain was normally placed. When we observed bath temperatures of more than $\sim 27^{\circ} \mathrm{C}$, the temperature directly below the objective would have already reached $\sim 33^{\circ} \mathrm{C}$ (data not shown). Therefore, the temperature at which the second responses of the $\mathrm{AC}$ neurons were observed was close to the Pyx-activating temperatures observed in vitro.

What is the function of Pyx neurons in the second antennal segments? The function of Pyx remains unclear because pyx mutants show normal temperature preference behavior (Fig. 6) (Lee et al., 2005) and normal noxious heat avoidance behavior (Neely et al., 2011). Drosophila are ectotherms and therefore rapidly change their body temperature by adapting to the ambient temperature. When flies encounter high temperatures, they need to avoid them as soon as possible, before their internal body temperatures increase to a harmful level. To prevent this danger, a redundant defense system may be necessary. Because Pyx neurons are located in the second antennal segments, which are easily influenced by ambient temperatures, we suspect that Pyx neurons may modulate activity of the AC neurons (Narayan et al., 2011; Bargmann, 2012) or may function as a "prewarning" mechanism to avoid harmful high-temperature environments.

The thermosensory neurons may not only function to detect dangerous stimuli but also affect one of the homeostatic regulations of the animal, such as its circadian rhythm. Ambient temperature fluctuations can entrain the peripheral clocks in mammals (Brown et al., 2002; Buhr et al., 2010) and both the peripheral and central clocks in flies (Glaser and Stanewsky, 2005; Yoshii et al., 2005; Busza et al., 2007; Miyasako et al., 2007; Zhang et al., 2010). However, it remains unclear how temperature information is transmitted to the clock cells. In Drosophila, the gene nocte is expressed in the chordotonal organs and has been found to be critical for temperature entrainment of the circadian clock (Sehadova et al., 2009). Although the involvement of the chordotonal organ in the second antennal regions is not firmly established, the presence of pyx-Gal4 in the chordotonal organ of the second antennal segment may raise the possibility that Pyx plays a role in temperature entrainment of the circadian clock.

Animals coordinate their behavior based on variable temperature inputs. The function of thermoTRP channels is critical for temperature sensation and behavioral plasticity, as is proper temperature integration into neural circuits. This work will help establish a foundation for temperature processing and may facilitate the identification of mechanisms involved in other sensory integration systems, such as multimodal sensory integration.

\section{References}

Altner H, Loftus R (1985) Ultrastructure and function of insect thermo-and hygroreceptors. Annu Rev Entomol 30:273-295. CrossRef

Altner H, Routil C, Loftus R (1981) The structure of bimodal chemo-, thermo-, and hygroreceptive sensilla on the antenna of Locusta migratoria. Cell Tissue Res 215:289-308. Medline

Bargmann CI (2012) Beyond the connectome: how neuromodulators shape neural circuits. Bioessays 34:458-465. CrossRef Medline

Beverly M, Anbil S, Sengupta P (2011) Degeneracy and neuromodulation among thermosensory neurons contribute to robust thermosensory be- haviors in Caenorhabditis elegans. J Neurosci 31:11718-11727. CrossRef Medline

Brown SA, Zumbrunn G, Fleury-Olela F, Preitner N, Schibler U (2002) Rhythms of mammalian body temperature can sustain peripheral circadian clocks. Curr Biol 12:1574-1583. CrossRef Medline

Buhr ED, Yoo SH, Takahashi JS (2010) Temperature as a universal resetting cue for mammalian circadian oscillators. Science 330:379-385. CrossRef Medline

Busza A, Murad A, Emery P (2007) Interactions between circadian neurons control temperature synchronization of Drosophila behavior. J Neurosci 27:10722-10733. CrossRef Medline

Caterina MJ (2007) Transient receptor potential ion channels as participants in thermosensation and thermoregulation. Am J Physiol Regul Integr Comp Physiol 292:R64-R76. CrossRef Medline

Damann N, Voets T, Nilius B (2008) TRPs in our senses. Curr Biol 18: R880-R889. CrossRef Medline

Dhaka A, Viswanath V, Patapoutian A (2006) TRP ion channels and temperature sensation. Annu Rev Neurosci 29:135-161. CrossRef Medline

Dillon ME, Wang G, Garrity PA, Huey RB (2009) Review: thermal preference in Drosophila. J Therm Biol 34:109-119. CrossRef Medline

Effertz T, Wiek R, Göpfert MC (2011) NompC TRP channel is essential for Drosophila sound receptor function. Curr Biol 21:592-597. CrossRef Medline

Gallio M, Ofstad TA, Macpherson LJ, Wang JW, Zuker CS (2011) The coding of temperature in the Drosophila brain. Cell 144:614-624. CrossRef Medline

Garrity PA, Goodman MB, Samuel AD, Sengupta P (2010) Running hot and cold: behavioral strategies, neural circuits, and the molecular machinery for thermotaxis in C. elegans and Drosophila. Genes Dev 24:2365-2382. CrossRef Medline

Glaser FT, Stanewsky R (2005) Temperature synchronization of the Drosophila circadian clock. Curr Biol 15:1352-1363. CrossRef Medline

Gong Z, Son W, Chung YD, Kim J, Shin DW, McClung CA, Lee Y, Lee HW, Chang DJ, Kaang BK, Cho H, Oh U, Hirsh J, Kernan MJ, Kim C (2004) Two interdependent TRPV channel subunits, inactive and Nanchung, mediate hearing in Drosophila. J Neurosci 24:9059-9066. CrossRef Medline

Göpfert MC, Robert D (2002) The mechanical basis of Drosophila audition. J Exp Biol 205:1199-1208. Medline

Griffith LC (2012) Identifying behavioral circuits in Drosophila melanogaster: moving targets in a flying insect. Curr Opin Neurobiol 22:609614. CrossRef Medline

Hamada FN, Rosenzweig M, Kang K, Pulver SR, Ghezzi A, Jegla TJ, Garrity PA (2008) An internal thermal sensor controlling temperature preference in Drosophila. Nature 454:217-220. CrossRef Medline

Hong ST, Bang S, Hyun S, Kang J, Jeong K, Paik D, Chung J, Kim J (2008) cAMP signalling in mushroom bodies modulates temperature preference behaviour in Drosophila. Nature 454:771-775. CrossRef Medline

Kamikouchi A, Shimada T, Ito K (2006) Comprehensive classification of the auditory sensory projections in the brain of the fruit fly Drosophila melanogaster. J Comp Neurol 499:317-356. CrossRef Medline

Kamikouchi A, Inagaki HK, Effertz T, Hendrich O, Fiala A, Göpfert MC, Ito K (2009) The neural basis of Drosophila gravity-sensing and hearing. Nature 458:165-171. CrossRef Medline

Kim J, Chung YD, Park DY, Choi S, Shin DW, Soh H, Lee HW, Son W, Yim J, Park CS, Kernan MJ, Kim C (2003) A TRPV family ion channel required for hearing in Drosophila. Nature 424:81-84. CrossRef Medline

Kwon Y, Shim HS, Wang X, Montell C (2008) Control of thermotactic behavior via coupling of a TRP channel to a phospholipase C signaling cascade. Nat Neurosci 11:871-873. CrossRef Medline

Kwon Y, Shen WL, Shim HS, Montell C (2010) Fine thermotactic discrimination between the optimal and slightly cooler temperatures via a TRPV channel in chordotonal neurons. J Neurosci 30:10465-10471. CrossRef Medline

Lahiri S, Shen K, Klein M, Tang A, Kane E, Gershow M, Garrity P, Samuel AD (2011) Two alternating motor programs drive navigation in Drosophila larva. PLoS One 6:e23180. CrossRef Medline

Lee Y, Lee J, Bang S, Hyun S, Kang J, Hong ST, Bae E, Kaang BK, Kim J (2005) Pyrexia is a new thermal transient receptor potential channel endowing tolerance to high temperatures in Drosophila melanogaster. Nat Genet 37:305-310. CrossRef Medline

Luo L, Gershow M, Rosenzweig M, Kang K, Fang-Yen C, Garrity PA, Samuel 
AD (2010) Navigational decision making in Drosophila thermotaxis. J Neurosci 30:4261-4272. CrossRef Medline

Miyasako Y, Umezaki Y, Tomioka K (2007) Separate sets of cerebral clock neurons are responsible for light and temperature entrainment of Drosophila circadian locomotor rhythms. J Biol Rhythms 22:115-126. CrossRef Medline

Narayan A, Laurent G, Sternberg PW (2011) Transfer characteristics of a thermosensory synapse in Caenorhabditis elegans. Proc Natl Acad Sci U S A 108:9667-9672. CrossRef Medline

Neely GG, Hess A, Costigan M, Keene AC, Goulas S, Langeslag M, Griffin RS, Belfer I, Dai F, Smith SB, Diatchenko L, Gupta V, Xia CP, Amann S, Kreitz S, Heindl-Erdmann C, Wolz S, Ly CV, Arora S, Sarangi R, et al. (2010) A genome-wide Drosophila screen for heat nociception identifies alpha2delta3 as an evolutionarily conserved pain gene. Cell 143:628-638. CrossRef Medline

Neely GG, Keene AC, Duchek P, Chang EC, Wang QP, Aksoy YA, Rosenzweig M, Costigan M, Woolf CJ, Garrity PA, Penninger JM (2011) TrpA1 regulates thermal nociception in Drosophila. PLoS One 6:e24343. CrossRef Medline

Ng M, Roorda RD, Lima SQ, Zemelman BV, Morcillo P, Miesenböck G (2002) Transmission of olfactory information between three populations of neurons in the antennal lobe of the fly. Neuron 36:463-474. CrossRef Medline

Olsen SR, Wilson RI (2008) Cracking neural circuits in a tiny brain: new approaches for understanding the neural circuitry of Drosophila. Trends Neurosci 31:512-520. CrossRef Medline

Patapoutian A, Peier AM, Story GM, Viswanath V (2003) ThermoTRP channels and beyond: mechanisms of temperature sensation. Nat Rev Neurosci 4:529-539. CrossRef Medline

Ramot D, MacInnis BL, Goodman MB (2008) Bidirectional temperaturesensing by a single thermosensory neuron in C. elegans. Nat Neurosci 11:908-915. CrossRef Medline

Rosenzweig M, Brennan KM, Tayler TD, Phelps PO, Patapoutian A, Garrity PA (2005) The Drosophila ortholog of vertebrate TRPA1 regulates thermotaxis. Genes Dev 19:419-424. CrossRef Medline

Rosenzweig M, Kang K, Garrity PA (2008) Distinct TRP channels are required for warm and cool avoidance in Drosophila melanogaster. Proc Natl Acad Sci U S A 105:14668-14673. CrossRef Medline

Sayeed O, Benzer S (1996) Behavioral genetics of thermosensation and hygrosensation in Drosophila. Proc Natl Acad Sci U S A 93:6079-6084. CrossRef Medline

Sehadova H, Glaser FT, Gentile C, Simoni A, Giesecke A, Albert JT, Stanewsky $R$ (2009) Temperature entrainment of Drosophila's circadian clock involves the gene nocte and signaling from peripheral sensory tissues to the brain. Neuron 64:251-266. CrossRef Medline
Shanbhag SR, Singh K, Singh RN (1995) Fine structure and primary sensory projections of sensilla located in the sacculus of the antenna of Drosophila melanogaster. Cell Tissue Res 282:237-249. CrossRef Medline

Shen WL, Kwon Y, Adegbola AA, Luo J, Chess A, Montell C (2011) Function of rhodopsin in temperature discrimination in Drosophila. Science 331:1333-1336. CrossRef Medline

Sokabe T, Tsujiuchi S, Kadowaki T, Tominaga M (2008) Drosophila painless is a $\mathrm{Ca}^{2+}$-requiring channel activated by noxious heat. J Neurosci 28 : 9929-9938. CrossRef Medline

Sugi T, Nishida Y, Mori I (2011) Regulation of behavioral plasticity by systemic temperature signaling in Caenorhabditis elegans. Nat Neurosci 14: 984-992. CrossRef Medline

Sun Y, Liu L, Ben-Shahar Y, Jacobs JS, Eberl DF, Welsh MJ (2009) TRPA channels distinguish gravity sensing from hearing in Johnston's organ. Proc Natl Acad Sci U S A 106:13606-13611. CrossRef Medline

Tian L, Hires SA, Mao T, Huber D, Chiappe ME, Chalasani SH, Petreanu L, Akerboom J, McKinney SA, Schreiter ER, Bargmann CI, Jayaraman V, Svoboda K, Looger LL (2009) Imaging neural activity in worms, flies and mice with improved GCaMP calcium indicators. Nat Methods 6:875881. CrossRef Medline

Tracey WD Jr, Wilson RI, Laurent G, Benzer S (2003) painless, a Drosophila gene essential for nociception. Cell 113:261-273. CrossRef Medline

Venkatachalam K, Montell C (2007) TRP channels. Annu Rev Biochem 76: 387-417. CrossRef Medline

Viswanath V, Story GM, Peier AM, Petrus MJ, Lee VM, Hwang SW, Patapoutian A, Jegla T (2003) Opposite thermosensor in fruitfly and mouse. Nature 423:822-823. CrossRef Medline

Walker RG, Willingham AT, Zuker CS (2000) A Drosophila mechanosensory transduction channel. Science 287:2229-2234. CrossRef Medline

Yorozu S, Wong A, Fischer BJ, Dankert H, Kernan MJ, Kamikouchi A, Ito K, Anderson DJ (2009) Distinct sensory representations of wind and nearfield sound in the Drosophila brain. Nature 458:201-205. CrossRef Medline

Yoshii T, Heshiki Y, Ibuki-Ishibashi T, Matsumoto A, Tanimura T, Tomioka K (2005) Temperature cycles drive Drosophila circadian oscillation in constant light that otherwise induces behavioural arrhythmicity. Eur J Neurosci 22:1176-1184. CrossRef Medline

Zars T (2001) Two thermosensors in Drosophila have different behavioral functions. J Comp Physiol A Neuroethol Sens Neural Behav Physiol 187: 235-242. CrossRef

Zhang Y, Liu Y, Bilodeau-Wentworth D, Hardin PE, Emery P (2010) Light and temperature control the contribution of specific DN1 neurons to Drosophila circadian behavior. Curr Biol 20:600-605. CrossRef Medline 